\title{
ISOLAMENTO DE GNAFALINA A PARTIR DE ACHYROCLINE ALATA (HBK) D. C. *
}

Luiz Bauer ${ }^{+}$, Catarina T.M. Bacha, Gilberto A. de A.B. e Silva, Norma C.S. de Siqueira e Belkis M.S. Sant'Ana

Departamento de Produção de Matēria Prima. Faculdade de Farmācia. UFRGS. Porto Alegre, RS.

RESUMO

Dos caules floridos de Achyrocline alata foi isolado um flavonōide e a sua estrutura foi determinada por comparação com amos tra autēntica de 5-hidroxi-7,8-dimetoxi-flavonol.

SUMMARY

BAUER, L.; BACHA, C.T.M.; SILVA, G.A.A.B.; SIQUEIRA, N.C.S.; and SANT' ANA, B.M. Isolation of gnafalina from Achyrocline alata (HBK)D.C. Ciência e Natura, 7:45-47.

A flavonoid was isolated from flowering stems of Achyro cline azata and structure was assigned to it by comparison with an authentic sample of 5-hydroxy-7,8-dimethoxy-favonol.

INTRODUÇÃO

Gnafalina (I) foi isolada por HANSEL e col. (1) (2) a par tir de Achyrocline satureoides. A sua estrutura foi determinada por espectrometria (IV, UV, RM ${ }^{1} H$ e EM), bem como, pela obtenção de deri vados.

A partir de Achyrocline alata, que tambēm è conhecida por "marcela" ou "macela" como a Achyrocline satureoides e muito usada em medicina popular como digestivo, carminativo, etc., foi isolada uma substância identificada como gnafalina (I), idêntica aquela en contrada em Achyrocline satureoides.

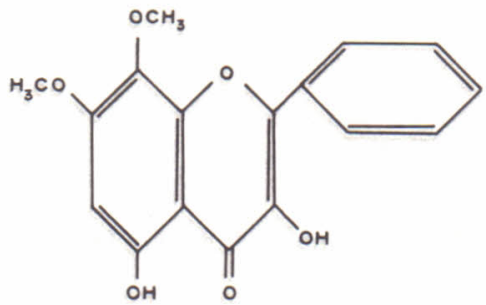

\footnotetext{
* Pesquisa realizada com apoio do CNPq.

+ in memorian.
} 
MATERIAL E METODOS

Os espectros de $\mathrm{RM}^{1} \mathrm{H}$ foram registrados em espectrômetro Varian, modelo EM $360 / 60 \mathrm{MHz}$, no Departamento de Química do ICEX (UFMG). Como solvente foi utilizado $\mathrm{CDCl}_{3}$, e TMS (tetrametilsitano) como referência interna. Os deslocamentos químicos foram anotados em unidade. O espectro de Massa foi registrado em espectrómetro Va rian, modelo $\mathrm{CH}-5$, existente no NPPN (UFRJ).

0 isolamento foi feito de $840 \mathrm{~g}$ de sumidades floridas, que esgotadas por etanol, forneceram $285 \mathrm{~g}$ de resíduo, apōs aliminação do solvente. Este, tratado com 2 litros de água fervente, foi fil trado. Da solução aquosa extraída com 6 litros de acetata de etila, resultou residuo de $18 \mathrm{~g}$ que foi tratado com sỉlica gel e extraỉdo com ēter etīlico. A fase etērea, após eliminação do solvente, ren deu um resíduo de $13,3 \mathrm{~g}$ que foi cromatografado em coluna de sîlica $(500 \mathrm{~g})$, com eluição por clorofōrmio, clorofōrmio-acetato de etila $(1: 1)$, e acetato de etila, coletando-se um total de 182 frações.

A fração 13, apōs concentração, apresentou um material sōlido, de coloração amarela, que por recristalização em etanol, levou ao isolamento de uma substāncia cristalina que foi designada AL-1 (22mg), de p.f. 174-1750. .

os dados espectroscópicos da substância isolada foram os seguintes:

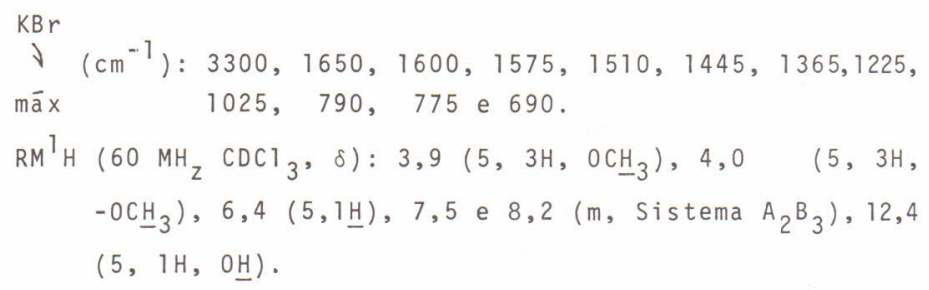

EM: M 314, m/e 300, 299, 295, 271, 256, 228, 167, 157, 149, $139,115,105,95,89,77,69$ e 63.

\section{RESULTADOS}

AL-1 foi comparado com amostra autêntica de gnafalina (I). A comparação desta com Al-1, mostrou identidade de comportamento em cromatografia em camada delgada de sîlica; os seus espectros no in fravermelho, ressonāncia magnética de prōtons e espectrometria de massa tambēm foram idēnticos (2).

CONCLUSÃO

A partir de caules floridos de Achyrocline alata, foi iso lada AL-1, substāncia identificada como 5-hidro-7,8-dimetoxy-flavo nol (I), que jā havia sido denominada gnafalina (I) por Hänsel, R. (1). 
AGRADECIMENTOS

A equipe agradece a Prof $\stackrel{\text { a }}{\text { Dra. Dorila P. Velloso (UFMG) }}$ pela realização dos espectros no IV, $\mathrm{RM}^{1} \mathrm{H}$ e Em., ao Prof. Dr. Rudolf Hănsel (Frein Universităt, Berlin) e ao Prof.Dr. Ali. H. Meriçli (I s tanbul Universitesi Eczacilik Fakultesi - Universite Istanbul, Tur kei), pelo envio dos padrões.

BIBLIOGRAFIA CITADA

1. HÄNSEL, R. \& OHLENDORF, D. B-ring unsubstituirte Flavone aus Gnafalium obtusifolium. Tetrahedron Letters. 0xford. (6): 431-2, 1969.

2. HÄNSEL, R. \& OHLENDORF, D. Ein neues im Ring $\beta$ unsubstituiertes Flavon aus Achyrocline satureoides. Archib der Pharmazie. Weinheim. 304(12):893-6, 1971.

Recebido em julho, 1985; aceito em agosto, 1985. 
